\title{
EVALUASI IMPLEMENTASI KEBIJAKAN PROGRAM PENDIDIKAN PIMPINAN TINGKAT NASIONAL PADA LEMBAGA KETAHANAN NASIONAL REPUBLIK INDONESIA
}

\author{
Rusmali Anggawiria ${ }^{1}$
}

\begin{abstract}
National Resilience Institute Republic of Indonesia as education providers focus on the education program cadreled national level, the appropriate duties and functions of educating, preparing cadres and strengthen the leadership of the national level through educational programs, so that the necessary preparation of the infrastructure of education, educational operations, development of educational materials and teacher. In this paper focuses on policy implementation leadership education programs with sub-national level focus include: 1). Supporter infrastructure management education. 2). Preparation of Educational Material. 3) .Governance/educational operations. 4). Performance faculty or holder teachings material. In the evaluative research using the model Discrepancy Evaluation Model (DEM), through the stages of Design Stage, Installed Programs, Process and Product. Based on the evaluation of research in the field, the researcher recommends 1). The need to increase both the quality and quantity of Infrastructures Education. 2). The need to increase the quality and ease of getting material Doctrine. 3). Operational management of the need to improve education. 4). The need to improve the appearance and teaching methods in the aspect of teaching staff personnel and Manpower Professional reviewers. National Resilience Institute of Republic of Indonesia is the appropriate institution be a leading sector in implementing the mental revolution because during this time the duties and functions of the Indonesian National Resilience Institute will educate the nation's leading cadres both from the political parties, the government and private sectors.
\end{abstract}

Keywords: Design Stage, Installed Programs, Process and Product. Infrastructure, Operations Education, educational materials and Holder Material/Lecturer

\section{PENDAHULUAN}

Berdasarkan peran dan kewenangannya, Lemhannas RI mempunyai tugas menyelenggarakan pendidikan dan pelatihan dalam rangka menghasilkan kader dan pemimpin bangsa sesuai dengan nilai-nilai kebangsaaan serta pembinaan kepada masyarakat dalam rangka pemantapan nilai-nilai kebangsaan. Dalam rangka menjalankan tugas tersebut maka terdapat beberapa tujuan yang akan dicapai dalam Renstra 2015-2019 Lemhannas RI, yaitu:

1) Meningkatkan kualitas penyelenggaraan pendidikan tingkat nasional bagi kader/calon-calon pimpinan tingkat nasional; 2) Meningkatkan kualitas pemantapan nilai-nilai kebangsaan 3) meningkatkan keberhasilan pelaksanaan koordinasi kebijakan ketahanan nasional lainnya sesuai peran dan tupoksi Lemhannas( Perencanaan Strategis Lemhannas RI Periode tahun 2015-2019: 5).

Indonesia saat ini memerlukan sosok pimpinan yang berintegritas secara moral dan berkapabilitas dalam mewujudkan pemerintahan Negara Indonesia yang melindungi segenap bangsa Indonesia $r \cdots \cdots$ masyarakat yang sejahtera, bangsa yang

\footnotetext{
${ }^{1}$ Direktur Evaluasi Pendidikan, Deputi Pendidikan Pimpinan Tingkat Nasional Lemhannas RI.
} 
cerdas, dan berkeadilan sosial sesuai dengan cita-cita proklamasi kemerdekaan Indonesia sebagaimana tercantum dalam pembukaan UUD tahun 1945 . Masalah yang muncul adalah bagaimana caranya agar lahir kader-kader pimpinan nasional yang memiliki wawasan kebangsaan tinggi, profesional, memiliki kapasitas dan kapabilitas sehingga akan mampu mengemban amanah dan tujuan dari berdirinya NKRI.

Lemhannas RI sebagai penyelenggara pendidikan focus terhadap program pendidikan kader pimpinan tingkat nasional, sesuai tugas pokok dan fungsinya mendidik, menyiapkan kader dan memantapkan pimpinan tingkat nasional melalui program pendidikan, sehingga perlu penyiapan sarana prasarana pendidikan, operasional pendidikan, pembinaan materi pendidikan dan pengajar serta evaluasi. Berkenaan dengan Evaluasi implementasi kebijakan program pendidikan pimpinan tingkat nasional Lemhannas RI dengan mengungkap tanggapan peserta pendidikan dari materi yang berkaitan langsung dengan para peserta pendidikan meliputi:

1. Bagaimana pengelolaan sarana prasarana pendukung pendidikan yang tersedia di Lemhannas RI.?

2. Bagaimana tata kelola/ operasional pendidikan dalam program pendidikan pimpinan tingkat nasional Lemhannas RI.?

3. Bagaimana kinerja Tenaga Pengajar atau pengampu/ Pemegang Materi Ajaran dalam program pendidikan pimpinan tingkat nasional Lemhannas RI.?

Penelitian/ hasil evaluasi ini, diharapkan dapat berguna bagi Lembaga Ketahanan Nasional RI dalam rangka peningkatan kualitas dan kuantitas dari fokus dan sub fokus hasil penelitian

\section{Konsep Manajemen Program}

Pengertian program menurut Levin (2013:3) adalah sebagai berikut, "a program consists of a set of related projects and required organizational changes to reach a strategic goal and to achieve the defined business benefits. The change character is apparent, as many organizational change initiatives are successfully implemented as programs." Program terdiri dari serangkaian proyek yang terkait dan diperlukan untuk perubahan organisasi dalam mencapai tujuan strategis dan untuk mencapai manfaat usaha yang ditetapkan. Perubahan karakter sebagai dampak dari suatu program akan tampak, karena banyak inisiatif perubahan organisasi yang telah berhasil diimplementasikan sebagai program. Untuk mencapai keberhasilan program, diperlukan mekanisme pengelolaan program (program management) yang tepat. menurut Lawson dan Gray (2011:7), "program management is the process of managing a group of on going, interdependent, related projects in coordinated way to achieve strategic objectives. Manajemen program adalah proses pengelolaan sekelompok proyek yang sedang berlangsung, saling bergantung, terkait dengan cara yang terkoordinasi untuk mencapai tujuan strategis.Program management is the centralized coordinated management of a program to achieve the program's strategic benefits and objectives. In addition, it allows for the application of several broad management themes to help ensure the successful accomplishment of the program. These themes are: benefits management, stakeholder management, and program governance.

Manajemen program adalah proses pengelolaan program yang dilakukan secara terkoordinasi dan terpusat untuk mencapai tujuan strategis dan manfaat program. Selain itu, memungkinkan untuk diterapkannya beberapa tema manajemen program yang luas untuk membantu memastikan tercapainya keberhasilan program. Tema-tema ini meliputi: manajemen manfaat, manajemen pemangku kepentingan, dan tata kelola program. Penjelasan setiap tema adalah sebagai berikut, "benefits management: (1) assesses 
the value and organizational impact of the program; (2) identifies the interdependencies of benefits being delivered among various projects within the program; (3) ensures that targeted benefits are specific, measurable, actual, realistic, and time-based; (4) analyzes the potential impact of planned program changes on benefits outcome; (5) assigns responsibilities and accountability for the actual benefits required from the program."Manajemen manfaat meliputi: (1) mengukur nilai dan dampak organisasional program; (2) mengidentifikasi saling ketergantungan manfaat yang diberikan antar proyek dalam program; (3) memastikan bahwa sasaran manfaat bersifat spesifik, terukur, nyata, realistis dan sesuai waktu; (4) menganalisa dampak potensial dari perubahan program yang direncanakan terhadap manfaat keberhasilan program; (5) menetapkan tanggung jawab dan akuntabilitas untuk manfaat yang sebenarnya dibutuhkan dari program tersebut. Manajemen manfaat bertujuan untuk memastikan bahwa organisasi dapat mewujudkan dan mempertahankan manfaat dari investasi program, bahkan akan mengikutinya sampai dengan akhir siklus program. Manajer program harus melihat bahwa aktivitas transisi program memberikan manfaat lanjutan program dalam rangka operasi program yang sedang berlangsung.

Berdasarkan deskripsi konsep di atas, manajemen program adalah proses pengelolaan program yang dilaksanakan secara terpusat dan terkoordinasi untuk mencapai tujuan strategis dan manfaat program. Fokus area dalam manajemen program meliputi perencanaan program, manajemen manfaat, manajemen resiko, manajemen pemangku kepentingan, manajemen kinerja, manajemen perubahan organisasi, serta manajemen komunikasi dan tata kelola program.

\section{Program Pendidikan Pimpinan Tingkat Nasional}

Berdasarkan Peraturan Gubernur Lemhannas RI Nomor 01 Tahun 2015 tgl 2 Januari 2015 Tentang Petunjuk Pelaksanaan Program Kerja dan Anggaran Lemhannas RI TA 2015 dimana dalam salah satu penjelasan Visi Lemhannas adalah:

Proses menghasilkan kader dan pemimpin bangsa sesuai dengan nilai-nilai kebangsaan harus melibatkan stakeholders serta dilaksanakan secara akuntabel dan diarahkan untuk menyelesaikan permasalahan ketahanan nasional yang lebih baik.

Untuk mewujudkan visi Lemhannas RI diperlukan tindakan nyata sesuai penguatan peran Lemhannas RI dengan Misi: "Menyelenggarakan pendidikan kader pimpinan tingkat nasional yang berkarakter sesuai dengan paradigma nasional" Lemhannas RI sebagai penyelenggara pendidikan kader pimpinan tingkat nasional, mempunyai tugas pokok menyelenggarakan pendidikan penyiapan kader dan pemantapan pimpinan tingkat nasional yang berfikir integratif dan profesional, memiliki watak, moral dan etika kebangsaan, berwawasan nusantara serta mempunyai cakrawala pandang universal. Dalam melaksanakan tugas tersebut, Lemhannas RI menyelenggaran fungsi: mendidik, menyiapkan kader dan memantapkan pimpinan tingkat nasional melalui program pendidikan, penyiapan materi pendidikan, operasi pendidikan dan pembinaan peserta serta evaluasi. Implementasi Program pendidikan melalui perangkat kendali berdasarkan Keputusan Gubernur Lemhannas RI Nomor 23 Tahun 2015 tanggal 12 Pebruari 2015 Tentang Perangkat Kendali Program Pendidikan Reguler Angkatan (PPRA) LIII Tahun 2015 Lemhannas RI, sebagai dasar dalam implementasi kebijakan program pendidikan pimpinan tingkat nasional dengan sisitimatika sebagai berikut:

Nama Program : Program Pendidikan Reguler Angkatan(PPRA) LIII Lemhannas RI Tahun 2015 


\section{Periode Pendidikan:}

a. Periode-I Off Campus (Pembelajaran Jarak Jauh/E-Learning) 1 (satu) bulan (4 (empat) minggu) $=18$ unit @120 menit

b. Periode-II On Campus(di Lemhannas RI) 6,5 bulan (32 minggu) = 407 unit@120 menit

c. Pelaksanaan pendidikan dimulai tanggal 3 Maret 2015 s/d tangal 29 Oktober 2015

\section{Tujuan Pendidikan}

Program Pendidikan Reguler Angkatan (PPRA) merupakan pendidikan untuk menyiapkan pimpinan tingkat nasional yang berkarakter negarawan, memiliki pengetahuan/wawasan strategis, dan terampil di dalam memecahkan masalah-masalah strategis (lingkup) global, regional dan nasional. Metode atau strategi pencapaian tujuan dilakukan melalui proses pembelajaran yang mengintegrasikan antara kepribadian dan penegetahuan serta ketrampilan dengan memanfaatkan ilmu pengetahuan dan teknologi. Dengan demikian, setiap peserta dituntut untuk aktif dan mandiri dalam mengaktualisaskan segenap potensi kemampuannya dengan baik. Metode pembelajaran yang digunakan adalah ceramah, diskusi panel, diskusi pendalaman, diskusi kelompok, diskusi antar kelompok, peninjauan lapangan dan pembinaan peserta.

\section{Sasaran Pendidikan}

1. Terwujudnya pimpinan tingkat nasional yang berkarakter kebangsaan, memiliki pengetahuan yang unggul dan wawasan yang dilandasi paradigma nasional.

2. Terampil dalam memecahkan masalah-masalah strategis (strategic problems).

3. Menjadi manajer handal yang menguasai perencanaan strategik.

\section{Pentahapan Program}

Program pendidikan pimpinan tingkat nasional reguler angkatan LIII (PPRA LIII) dibagi kedalam 4 tahap yang terdiri dari:

1. Blok I: Menghasilkan pimpinan yang berkarakter negarawan melalui 6 bidang studi inti sebagai landasan dalam kegiatan perencanaan dan pelaksanaan terhadap setiap isu-isu kehidupan berbangsa dan bernegara dalam kerangka Negara Kesatuan Republik Indonesia berdasarkan Pancasila dan UUD NRI Tahun 1945. Pada tahap ini peserta akan melaksanakan Pengenalan Objek Strategis (POS).

2. Blok II: Menghasilkan pimpinan yang berkarakter negarawan, memiliki pengetahuan dan kemampuan analisis strategis. Pada tahap ini peserta akan melaksanakan Studi Strategis Dalam Negeri (SSDN).

3. Blok III: Menghasilkan pimpinan yang berkarakter negarawan, memiliki pengetahuan dan kemampuan analisis strategis dan memecahkan masalah strategis. Pada tahap ini peserta akan melaksanakan Studi Strategis Luar Negeri (SSLN).

4. Blok IV: Menghasilkan manajer handal yang mempunyai kemampuan dalam penyusunan kebijakan dan pengambilan keputusan tingkat nasional. Secara individu akan melaksanakan uji tulis dan uji saji Taskap, secara kelompok melaksanakan Program Pilihan, Olah Sismennas dan dalam forum besar melaksanakan Seminar.

\section{Evaluasi Program}


Dalam penulisan ini digunakan Evaluasi Model Kesenjangan (Discrepancy Evaluation Model (DEM).) yang dikembangkan oleh Malcolm Provus, menurut Provus (dalam Fernandes, 1984) model ini digunakan untuk mengetahui tingkat kesesuaian antara baku (standard) yang sudah ditentukan dalam program dengan kinerja (performance) sesungguhnya dari program tersebut. Baku adalah kriteria yang ditetapkan, sedangkan kinerja adalah hasil pelaksanaan program. Oleh karena itu model evaluasi ini memiliki lima tahap yaitu desain, instalasi, proses, produk dan membandingkan. Sedangkan kesenjangan yang dapat dievaluasi dalam program pendidikan meliputi; (1) kesenjangan antara rencana dengan pelaksanaan program; (2) Kesenjangan antara yang diduga atau diramalkan akan diperoleh dengan yang benarbenar direalisasikan; (3) Kesenjangan antara status kemampuan dengan standar kemampuan yang ditentukan; (4) Kesenjangan tujuan, (5) Kesenjangan mengenai program yang akan diubah, (6) Kesenjangan dalam sistem yang tidak konsisten.

Argumentasi Provus, bahwa semua program memiliki daur hidup (life cycle). Karena program terdiri atas langkah-langkah pengembangan, aktivitas evaluasi banyak diartikan adanya integrasi pada masing-masing komponennya.

1. Dalam tahap definisi (definition stage), staf program mengorganisir a) gambaran tujuan, proses, atau aktivitas dan kemudian b) menggambarkan sumber daya yang diperlukankan. Harapan atau standar ini adalah dasar dimana evaluasi berkelanjutan tergantung.

2. Dalam langkah instalasi (installation stage), desain/ definisi program menjadi standar baku untuk diperbandingkan dengan penilaian operasi awal program. Gagasannya adalah untuk menentukan sama dan sebangun, sudah atau tidaknya program telah diterapkan sebagaimana desainnya.

3. Dalam tahap proses(Proses stage), evaluasi ditandai dengan pengumpulan data untuk menjaga keterlaksanaan program. Gagasannya adalah untuk memperhatikan kemajuan kemudian menentukan dampak awal, pengaruh, atau efek.

4. Dalam tahap produk (product stage), pengumpulan data dan analisa yang membantu ke arah penentuan tingkat capaian sasaran dari outcome. Dalam tahap 4 ini pertanyaannya adalah "Apakah sasaran program telah dicapai?" Harapannya adalah untuk merencanakan follow up jangka panjang pemahaman atas dampak.

5. (optional) tahap cost-benefit menunjukkan peluang untuk membandingkan hasil dengan yang dicapai oleh pendekatan lain yang serupa.

\section{METODOLOGI}

Dalam hal penelitian evaluasi pendidikan (Cresweel 2012) menyatakan bahwa " Evaluation research involves assessing the quality of study using standards by individuals in education" Penelitian evaluasi adalah melakukan pengukuran terhadap kualitas sesuatu yang dipelajari menggunakan standar dan melibatkan induvidu-induvidu dalam pendidikan. Sugiyono (2014:740) Penelitian evaluasi dilakukan dengan tujuan untuk meningkatkan efektivitas suatu kebijakan atau program, berdasarkan umpan balik dari orang-orang yang terlibat dalam pelaksanaan program tersebut. Weiss (1973) menyatakan bahwa "It is important to note that evaluation research is basically what is commonly called programmed or project evaluation" Hal penting yang perlu dicatat bahwa, pada dasarnya penelitian evaluasi adalah merupakan evaluasi program atau proyek. Program evaluationisa systematic method for collecting, analyzing, and using programs, particularly about their effectiveness and efficiency. Evaluation Research: It has been used to test the effectiveness. Evaluasi program adalah merupakan metode yang sistematis untuk 
mengumpulkan data, menganalisis data, dan menggunakan informasi untuk menjawab pertanyaan tentang proyek, kebijakan dan program, khususnya yang terkait dengan efektifitas dan efisiensi. Penelitian evaluasi pada dasarnya adalah menguji efektifitas suatu program.

\section{HASIL PENELITIAN DAN PEMBAHASAN}

Berpedoman pada Program Kerja Lemhannas RI Tahun Anggaran 2015, Deputi Bidang Pendidikan Pimpinan Tingkat Nasional melaksanakan Program Kedeputian Pendidikan Tahun 2015 Lemhannas RI, yaitu Program Pendidikan Reguler Angkatan LIII (PPRA LIII) dengan tahapan pelaksanaan sebagai berikut:

Berdasarkan data peneliti di atas dan dibandingkan dengan pelaksanaan implementasi program pendidikan pimpinan tingkatat nasional Lemhannas RI PPRALII Tahun 2014 dan PPRA-LIII Tahun 2015 masih terdapat keluhan atau ketidakpuasan para peserta dalam implementasi program pendidikan pimpinan tingkat nasional Lemhannas RI.

Prinsip pengukuran sikap yaitu meminta peserta untuk menanggapi serangkaian pernyataan tentang suatu topik. Sejauh mana mereka setuju dengan memasuki komponen kognitif dan afektif. Skala Likert adalah teknik skala non-komparatif dan unidimensional yaitu hanya mengukur sifat tunggal. Responden dipaksa menunjukkan tingkat kesepakatan atas sebuah pernyataan menggunakan skala ordinal. Likert (1932) mengasumsikan sikap dapat diukur dan intensitas suatu pengalaman adalah linear yaitu duduk di sebuah kontinum dari sangat setuju sampai sangat tidak setuju.

\section{Data Angket Tahap-I dan Tahap II PPRA-52 dan PPRA-53}

\section{a. Aspek Sarana Prasarana.}

Berdasarkan data angket yang telah diolah dari sampel PPRA-52 dan PPRA-53 dari aspek sarana prasarana adalah sebagai berikut:

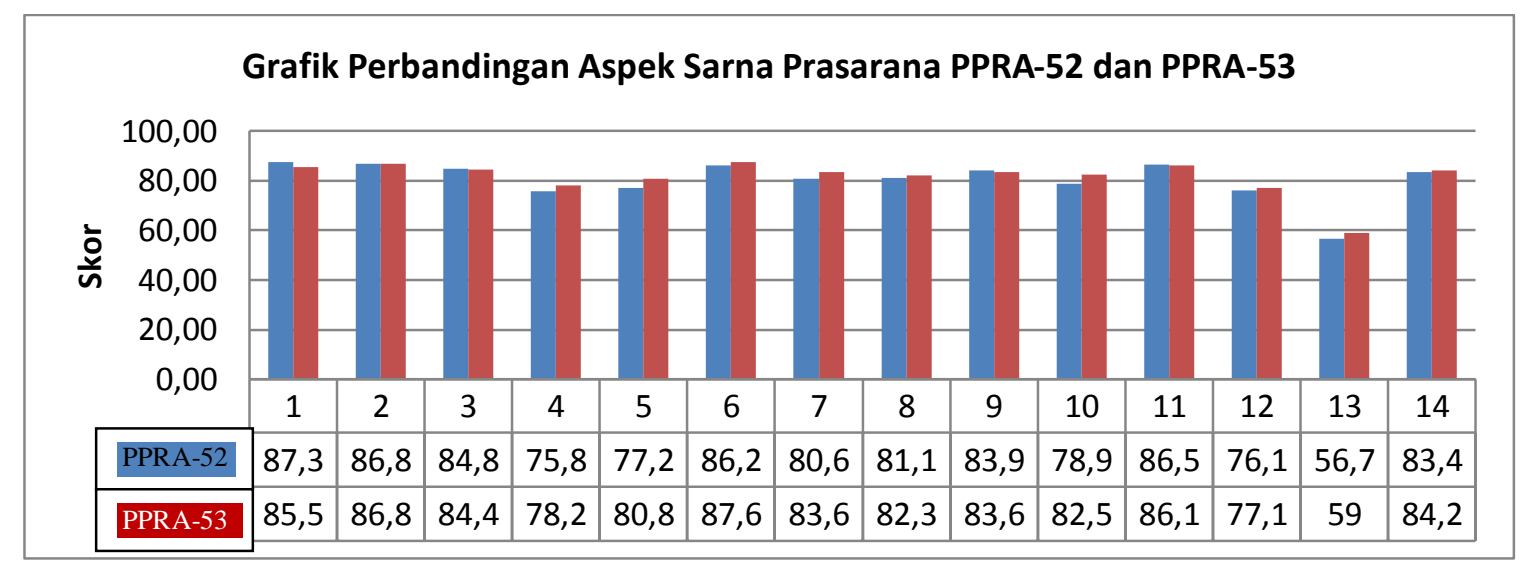

Jika melihat data di atas dapat digambarkan bahwa tingkat kepuasan ada kenaikan dari rata-rata 80,42 menjadi 81,53 ini menunjukan persepsi kepuasan para peserta ada peningkatan, walaupun dibeberapa bagian ada penurunan antara lain dari kesiapan ruang kelas, dari 87,36 turun menjadi 85,47; Sound system dan penyejuk ruangan/AC pendukung kegiatan kuliah dari 86,80 turun menjadi 80,75; Alat instruksi 
dan alat penolong instruksi yang digunakan pendukung kegiatan belajar mengajar dari 84,83 turun menjadi 84,40

\section{b. Aspek Materi Pendidikan.}

Berdasarkan data angket yang telah diolah dari sampel PPRA-52 dan PPRA-53 dari aspek materi pendidikan adalah sebagai berikut:

Jika melihat data pada grafik berdasarkan tingkat kepuasan para peserta sebagai unsur pemangku kepentingan sebagai objek dari evaluasi ini dari aspek Materi pendidikan maka dapat digambarkan bahwa tingkat kepuasan ada penurunan dari ratarata 85,29 menjadi 84,54 walaupun demikian ada unsur yang ada peningkatan antara lain: Referensi dan materi ajaran yang diberikan Tajar/taji/taprof Narasumber masih relevan dan faktual dari skor 80,90 naik menjadi 83,12; Materi ajaran yang diberikan mudah diterima dan dimengerti dan sesuai dengan tujuan dan sasaran pendidikan dari skor 79,49 naik menjadi 79,70.

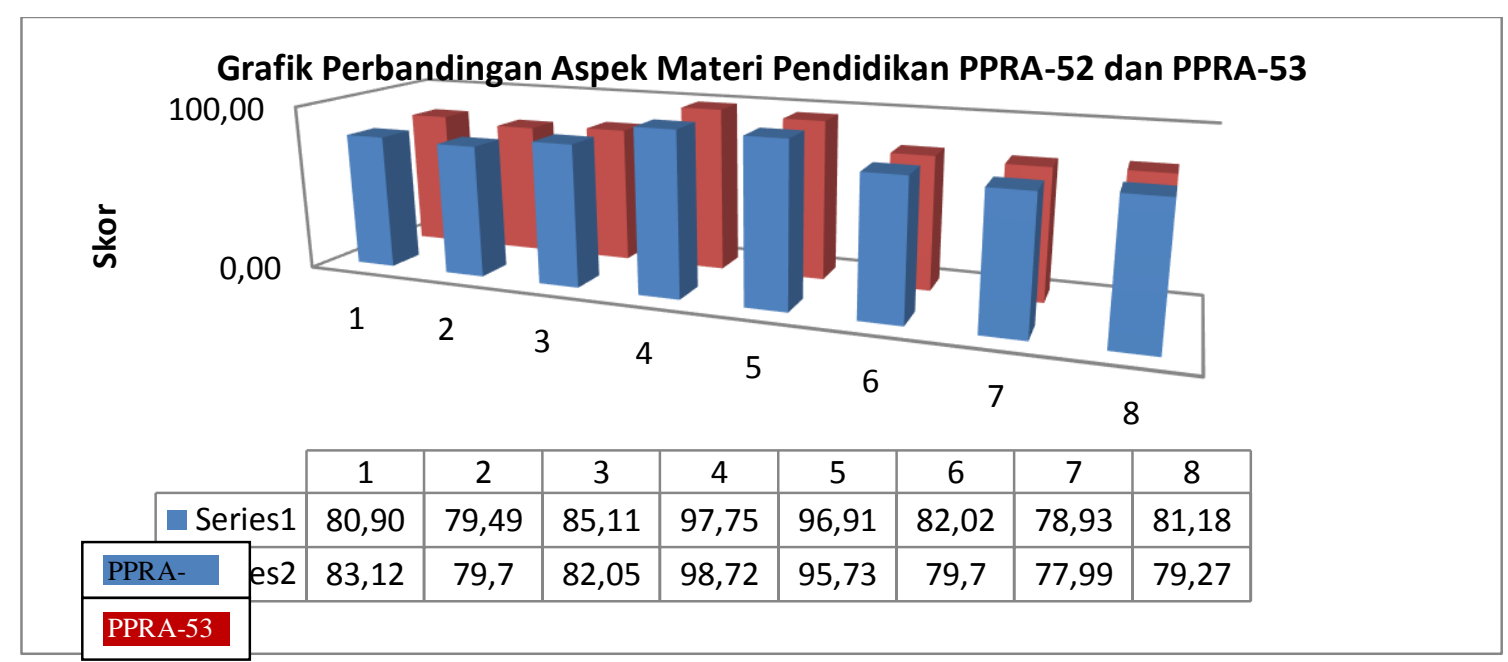

\section{c. Aspek Operasional Pendidikan.}

Berdasarkan data angket yang telah diolah dari sampel PPRA-52 dan PPRA-53 dari aspek materi pendidikan adalah sebagai berikut:

Jika melihat data grafik berdasarkan tingkat kepuasan para peserta sebagai unsur pemangku kepentingan sebagai objek dari evaluasi ini dari operasional pendidikan maka dapat digambarkan bahwa tingkat kepuasan ada penurunan dari rata-rata 84,40 menjadi 83,51 walaupun demikian ada unsur yang ada peningkatan antara lain: Pembagian waktu dalam kegiatan ceramah dan diskusi dari skor 79,78 naik menjadi 79,91; Waktu yang disediakan dalam merumuskan judul taskap dari skor 81,18 menjadi 81,20; Petunjuk teknis penulisan Taskap dari skor 82,58 menjadi 83,33 dan Kegiatan utama yang telah peserta ikuti sesuai dengan sasaran pendidikan dari skor 88,20 naik menjadi 89,10 


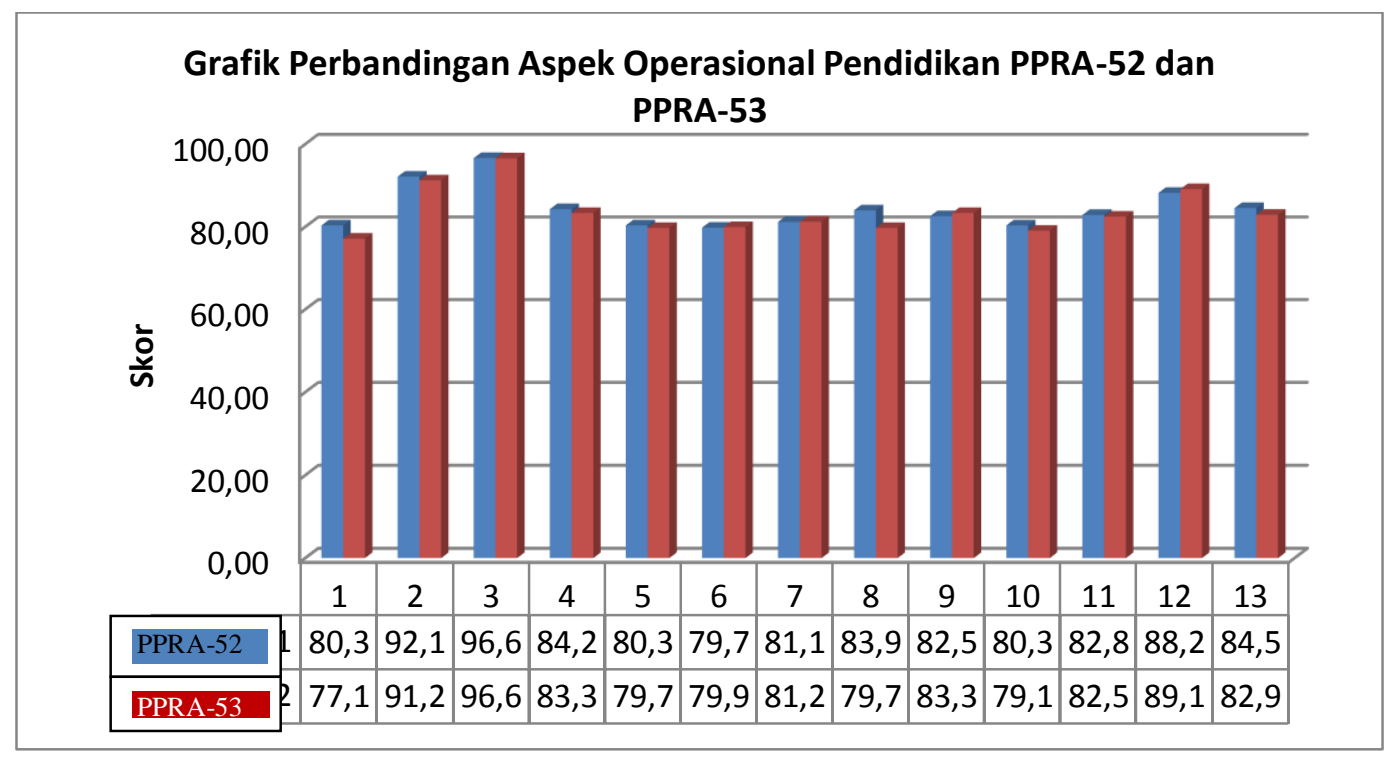

\section{d. Aspek Pembina Materi.}

Berdasarkan data angket yang telah diolah dari sampel PPRA-52 dan PPRA-53 dari aspek pembina materi pendidikan adalah sebagai berikut:

Jika melihat data pada grafik berdasarkan tingkat kepuasan para peserta sebagai unsur pemangku kepentingan sebagai objek dari evaluasi ini dari aspek pembina materi pendidikan maka dapat digambarkan bahwa tingkat kepuasan ada kenaikan dari ratarata skor 82,02 naik menjadi 82,97 walaupun demikian masih ada unsur yang menurun antara lain: Penguasaan materi ajaran oleh Tajar/Taji/Tarprof/Tutor/ Narasumber dari skor 83,15 menjadi 80,77; Kemampuan pendamping dan pembantu pendamping dalam membantu pelaksanaan kegiatan kelas dari skor 81,46 turun menjadi 79,27; Kemampuan Tutor pendamping/Narasumber dalam mengendalikan kegiatan diskusi dari nilai skor 80.62 turun menjadi 79,91 dan Tajar/Taji/Taprof/Narasumber pengganti/yang mewakili dari skor 77,25 turun menjadi 76,71

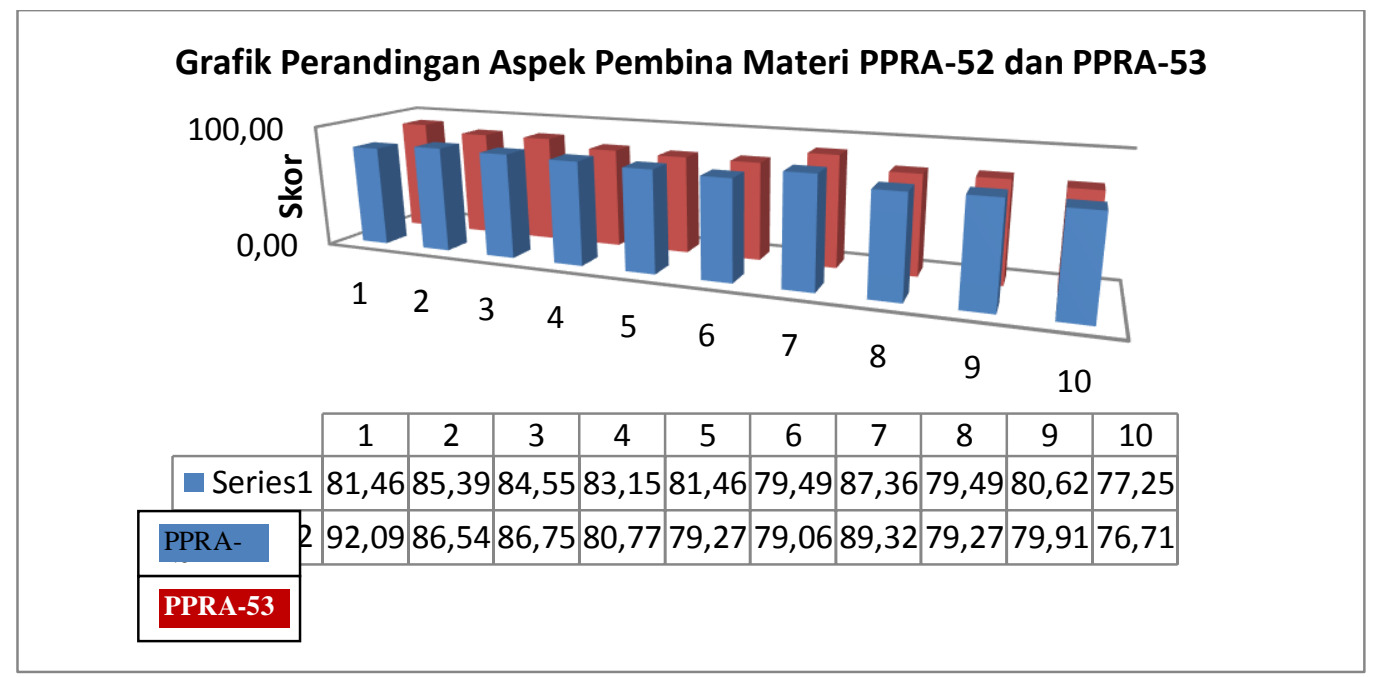

\section{e. Rekapitulasi Per Aspek.}

Berdasarkan data angket yang telah diolah dari sampel PPRA-52 dan PPRA-53 dari empat aspek pendidikan adalah sebagai berikut: 
Tabel Perbandingan Rekapitulasi Aspek Pendidikan PPRA-52 dan PPRA-53

\begin{tabular}{|l|l|l|l|}
\hline NO & $\begin{array}{l}\text { REKAPITULASI PER ASPEK } \\
\text { URAIAN }\end{array}$ & I & II \\
\hline I. & Aspek Sarana Prasarana Pendidikan & $\mathbf{8 0 . 4 2}$ & $\mathbf{8 1 . 5 3}$ \\
\hline II. & Aspek Materi Pendiddikan & $\mathbf{8 5 . 2 9}$ & $\mathbf{8 4 . 5 4}$ \\
\hline III. & Aspek Operasional Pendidikan & $\mathbf{8 4 . 4 0}$ & $\mathbf{8 3 . 5 1}$ \\
\hline IV. & Aspek Pembina Materi & $\mathbf{8 2 . 0 2}$ & $\mathbf{8 2 . 9 7}$ \\
\hline & Rata-rata & 83,03 & 83,14 \\
\hline
\end{tabular}

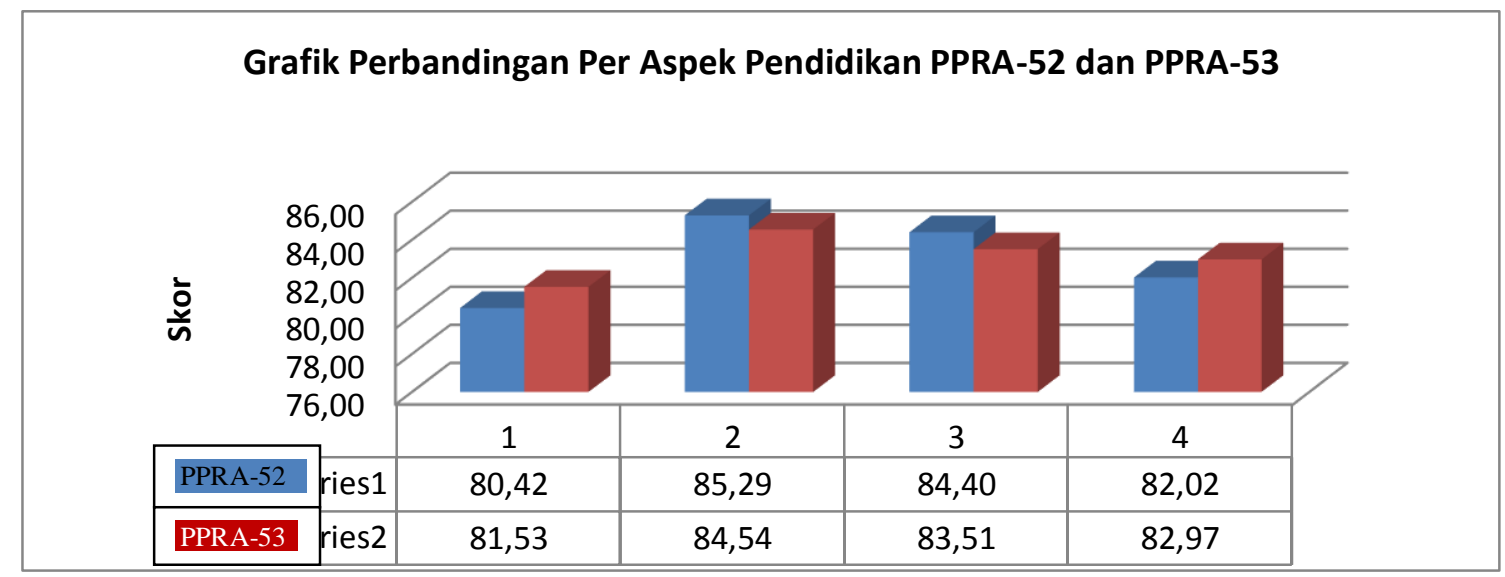

Berdasarkan analisa di atas dapat disimpulkan bahwa Implementasi Program Pendidikan di Lemhannas jika melihat ke empat aspek pendidikan dari sampel yang diamati yaitu dari aspek Sarana prasara pendidikan ada peningkatan dari skore 80,42 menjadi 81,53, dari aspek Materi pendidikan ada penurunan dari skor 85,29 menjadi 84,54, dari aspek Operasinal pendidikan ada penurunan dari skor 84,40 menjadi 83,51 dan dari aspek Pembina materi pendidikan ada peningkatan dari skor 82,02 menjadi 82,97 dengan demikian dari data di atas dapat gambaran bahwa Implementasi program pendidikan di Lemhannas ada peningkatan walaupun sangat tipis dari skor rata-rata 83,03 menjadi 83,14

\section{PENUTUP}

Kesimpulan: Berdasarkan analisa penilaian dapat disimpulankan bahwa dari empat Aspek yang diamati yaitu dari aspek Sarana prasara pendidikan ada peningkatan dari skore 80,42 menjadi 81,53, dari aspek Materi pendidikan ada penurunan dari skor 85,29 menjadi 84,54, dari aspek Operasinal pendidikan ada penurunan dari skor 84,40 menjadi 83,51 dan dari aspek Pembina materi pendidikan ada peningkatan dari skor 82,02 menjadi 82,97 dengan demikian dari data di atas dapat gambaran bahwa Implementasi kebijakan program pendidikan pimpinan tingkat nasional di Lemhannas pada tahun 2015 ada peningkatan terhadap kepuasan para peserta yang menjadi objek penelitian, dibandingkan dengan tahun 2014 walaupun sangat tipis dari skor rata-rata 83,03 menjadi 83,14 dengan Predikat Sangat Baik. 
Penelitian evaluasi ini menggunakan metode riset evaluasi dengan tujuan menilai dan menguji keterlaksanaan suatu program pendidikan atau efektifitas implementasi kebijakan program pendidikan pimpinan tingkat nasional pada Lemhannas RI. Untuk menjawab efektifitas suatu Program Pendidikan sesuai Program Kerja Lemhannas RI tentang Peraturan Gubenur Lemhannas RI Nomor 01 Tahun 2015 tgl 2 Januari 2015 tentang Petunjuk Pelaksanaan Program Kerja dan Anggaran Tahun 2015 Lemhannas RI. dan Surat Perintah Gubernur Lemhannas RI Nomor: Sprin/69/I/105 tanggal 15 Januari tentang Penyelenggaraan Program Pendidikan Reguler Angkatan (PPRA) LIII Tahun 2015 Lemhannas RI, melaui model evaluasi Discrepancy Evaluation Model (DEM).

Rekomendasi: Dari hasil Evaluasi Implementasi Kebijakan Program pendidikan Pimpinan Tingkat Nasional pada Lembaga Ketahanan Nasional Republik Indonesia dan berdasarkan penelitian di lapangan maka peneliti merekomendasikan dari hasil evaluasi sebagai berikut :

1. Aspek Sarana dan Prasarana Pendidikan.

a. Messing/kamar perlu secara rutin dibersihkan setiap hari walaupun libur, serta disediakan fasilitas dispenser umum di setiap lantai.

b. Perlunya pemeliharaan AC ruangan secara rutin secara berkala, agar kejadian matinya AC di lantai VII selama 2 bulan diharapkan tidak terulang kembali.

c. Wifi di kamar dan diruang-ruang kelas sering terjadi gangguan sehingga menjadi kendala dalam proses pendidikan agar pejabat yang diberi tanggung jawab lebih perhatian.

d. Ruang diskusi agar dilengkapi sound system yang memadai dan peralatan (papan tulis), perlunya Lembaga untuk mengadakan kebutuhan di ruang kelas .

e. Perlunya pembenahan ruang diskusi kelompok karena masih terdengar suara bising dari luar yang sangat menganggu.

f. Office boy pada ruang diskusi kurang memperhatikan kebersihan kamar mandi/wc/wastafel/lantai agar menjadi perhatian Lembaga.

g. Perlunya internet untuk selalu ontermasuk pada hari libur dan malam hari sehingga dapat membantu dalam penyelesaian tugas-tugas yang diberikan kepada para peserta pendidikan

h. Pemeliharaan lift di gedung mess (yang menuju ke Jl. Kebon sirih ke koperasi) perlu di tingkatkan.

i. Perlunya di cek kebersihan kelas setiap hari

j. Buku perpustakaan perlu penambahan referensi agar mampu mendukung kegiatan akademis.

2. Aspek Materi Ajaran.

a. Modul yang terdapat ringkasan perlu perbaikan sehingga saat di gunakan referensi bisa lebih jelas.

b. Modul/materi pokok perlu disempurnakan dan dibuatkan dalam bentuk buku dengan cover yang sesuai pada masing-masing modul (seperti pancasila dan UUD NRI 1945, wawasan nusantara dll).

c. Materi perlu terus di upgrade terutama terkait referensi dan kebijakan yang terbaru.

d. Diharapkan materi lebih diarahkan kepada visi dan misi pemerintah dan tidak seharusnya mengkritisi visi missi tersebut.

e. Materi bahaya laten komunis dan Ideologi lain yang mengancam Ideologi Pancasila perlu ditambahkan. 
f. Materi pendidikan tentang kepemimpinan perlu di tambah sehingga sasaran peningkatan kepemimpinan tingkat nasional dapat tercapai.

g. Materi pembelajaran sebaiknya disesuaikan dengan materi lingkungan strategis termasuk berbagai perundang-undangan yang terkait.

3. Aspek Operasional Pendidikan

a. Kegiatan ceramah, penceramah diuatamakan dari Kementrian atau LPNK dengan harapan menyampaikan materi yang berkaitan dengan kebijakan yang up to date termasuk isue-isue strategis

b. Kegiatan Diskusi; TOR sebagai bahan diskusi agar diberikan lebih awal,sehingga para Peserta dapat menyiapkan diri lebih awal, kesimpulan hasil diskusi dijadikan bahan referensi bagi peserta untuk penulisan makalah berikutnya, pada diskusi panel sebaiknya ada keynote speaker dan penanggap ahli agar terjalin lalu lintas informasi antara panel, dan waktu diskusi lebih banyak untuk menggali informasi melalui brainstorming selain tanya jawab.

c. Jadwal Pelajaran; waktu untuk pendalaman materi ajaran bidang studi inti agar ditambah; pengaturan jadwal yang melibatkan penceramah dari luar Lemhannas agar dikoordinasikan dengan baik agar tidak terjadi kekosongan kelas atau diganti oleh penceramah yang belum tentu tepat. perlunya penyampaian jadwal pelajaran bulanan agar peserta lebih baik dalam mempersiapkan; serta Koordinasi dan persiapan kegiatan SSDN dan SSLN agar lebih baik lagi.

d. Penugasan Peserta; Pemberian lembar penugasan diskusi setelah ceramah atau diskusi panel waktunya segera setelah selesai Ceramah atau Diskusi panel; Penugasan penulisan rangkuman dengan tulisan tangan perlu diganti dengan pendalaman materi; waktu penugasan esai perlu ditambah; Penugasan dan pengumuman sebaiknya juga diberikan lewat email selain dengan lembar cetakan; waktu kegiatan diskusi antar kelompok perlu ditambah; waktu penulisan Taskap juga perlu ditambah; termasuk pendalaman materi metodologi penulisan Taskap.

4. Aspek Tajar, Taji dan Tenaga Professional.

a. Perlunya bahan ajaran sebelum ceramah dimulai perlu dipersiapkan lebih awal untuk dibagikan sehingga pada saat ceramah dimulai para peserta sudah mempelajarinya lebih awal.

b. Penceramah/narasumber utama disarankan untuk dapat hadir dan tidak diwakilkan deputi/staf dibawahnya terutama narasumber dari K/L (Kementrian atau Lembaga)

c. Perlu peningkatan jumlah narasumber dari kementerian/menteri, selama ini hanya sebagian kecil yang dapat hadir untuk memberikan ceramah.

d. Agar penceramah tidak menyampaikan tentang materi yang termasuk rahasia negara jika siswa asing diizinkan ada di dalam kelas, agar kondisi ini menjadi perhatian pengampu materi.

e. Perlunya menyiapkan Narasumber selain yang memiliki kompetensi juga integritas serta pengalaman yang paripurna dibidangnya.

f. Perlunya sosialisasi juknis (Petunjuk Teknis) tentang Taskap lebih intensif bagi seluruh tajar/taji/taprof agar ada keseragaman pola pikir dalam kegiatan tutorial kepada peserta, sehingga peserta mudah untuk memahami dan tidak mencari figur atau kebenaran di lain tutor. 


\section{DAFTAR RUJUKAN}

Arikunto, Suharsimi. Evaluasi Program Pendidikan (edisi kedua). Jakarta: Bumi Aksara. 2014

Arnold J. Love, Internal Evaluation: Building Organiztion from Within (California: Sage Publication, 1991),

Daniel L. Stufflebeam, Anthony J. Shinkfield, Evaluation Theory, Models, and Applications (San Francisco: John Wiley and Sons, 2007),

Daniel L. Stufflebeam, George F. Madaus, Thomas Kellaghan (Eds), Evaluation Models Viewpoints on Educational and Human Services Evaluation (New York: Kluwer Academic Publishers, 2002)

David Royse, Bruce A. Thyer, Deborah K. Padgett, Program Evaluation: An Introduction (Canada: Cengage Learniong, 2010),

Djaali dan Puji Mulyono, Pengukuran dalam Bidang Pendidikan ( Jakarta: PPs UNJ, 2000)

Dudju Sudjana, Evaluasi Program Pendidikan Luar Sekolah (Bandung, UPI dan Remaja Rosdakarya, 2006),

Edgardo Gonzalez, "Performace Program Management", New Millennium Team ThinkingWhite Paper, Nov.2012Erik W. Larson, Clifford F. Gray, Project Management: The

Managerial Process (New York: McGraw-Hill Companies Inc., 2011

Eprint, "Model model evaluasi" UNY Online http:/ / eprints, uny.ac.id

Fernandes,. Evaluation of Educational Program. Jakarta: National Education Planning, Evaluation and Curriculum Development. H.J.X. 1984

Ginger Levin,Program Management: A Life Cycle Approach (New York: Taylor \& Francis Group, 2013),

Glyn Rogers, Linda Badham, Evaluation in Schools: Getting Started on Training and Implementation (New York: Routledge, 2004),

Judith D. Chapman, School-based Decision-making and Management (Hongkong: Palmer, 1990),

Joseph S. Wholey, Harry P. Hatry, Kathryn E. Newcorner, Handbook of Pratical Program Evaluation (New Jerseys: John Wiley \& Sons, Inc. 2010),

Lembaga Ketahanan Nasioan RI, Petunjuk Pelaksanaan Program Kerja dan Anggaran, TA 2015

Lemhannas RI Perencanaan Strategis periode tahun 2015-2019

Marvin C. Alkin, Evaluation Essentials: From A to Z (New York: The Guilford Press, 2011),

Michael Quinn Patton, Utilition- Focused Evaluation: The New Century Text (California: SAGE Publication, 1997)

Michelle Lindeman, Program Evaluation, 2011

Peter Hernon, Charles R. McClure, Evaluation and Library Decision Making (New Jersey: Albex Publisihing, 1994), 
Purwanto, . Evaluasi Hasil Belajar . Yogyakarta: Pustaka Pelajar.2009.

Project Management Institute, The Standard for Program Management (Pennsylvania: Project Management Institute, Inc, 2006),

Stufflebeam, D.L. H McKee dan B McKee. 2003. The CIPP Model for Evaluation . Paper presented at $t$ he 2003 Annual Conference of the Oregon Program Evaluation Network (OPEN). Portland, Oregon.

Tayibnapis,. Evaluasi Program . Rineka Cipta. JakartaF. Y. 2000. Dari berbagai sumber di internet melalui www.google.com

Thomas Kellaghan, Danil L. Stufflebeam, International Handbook of Educational Evaluation: Practice (Great Britain: Kluwer Academin Publiser, 2003) 